\title{
On the Use of the Repeated-Sprint Training in Hypoxia in Tennis
}

\begin{abstract}
Cyril Brechbuhl',2, Franck Brocherie ${ }^{3}$, Sarah J. Willis', Thomas Blokker2, Bernard Montalvan ${ }^{4}$, Olivier Girard ${ }^{5}$, Gregoire P. Millet ${ }^{2 *}$ and Laurent Schmitt ${ }^{2,6}$

${ }^{1}$ French Tennis Federation, Independent Researcher, Paris, France, ${ }^{2}$ Institute of Sports Science, University of Lausanne, Lausanne, Switzerland, ${ }^{3}$ EA7370 Laboratoire Sport, Expertise et Performance, Institut National du Sport, de l'Expertise et de la Performance, Paris, France, ${ }^{4}$ Fédération Française de Tennis (FFT), Paris, France, ${ }^{5}$ Faculty of Science, School of Human Sciences, University of Western Australia, Perth, Australia, ${ }^{6}$ Centre National de Ski Nordique et de Moyenne Montagne (CNSNMM), Prémanon, France
\end{abstract}

Purpose: To examine physiological and technical responses to repeated-sprint training in normobaric hypoxia at $\sim 3,000 \mathrm{~m}(\mathrm{RSH}, n=11)$ or in normoxia ( $\mathrm{RSN}, n=11$ ) compared to a control group (CON, $n=8)$ in well-trained tennis players. Participants were $28.8 \pm 5.9$ years old without any previous experience of training in hypoxia.

Methods: In addition to maintaining their usual training (CON), both RSH and RSN groups completed five tennis specific repeated-shuttle sprint sessions $(4 \times 5 \times \sim 8 \mathrm{~s}$ maximal sprints with $\sim 22 \mathrm{~s}$ passive recovery and $\sim 5$ min rest between sets) over 12 days. Before (Pre), the week after (Post-1) and 3 weeks after Post-1 (Post-2), physical/technical performance during Test to Exhaustion Specific to Tennis (TEST), repeated-sprint ability (RSA) $(8 \times \sim 20$ m shuttle runs-departing every $20 \mathrm{~s})$ and heart rate variability (HRV) were assessed.

Results: From Pre to Post-1 and Post-2, RSH improved TEST time to exhaustion (+18.2 and $+17.3 \%$; both $P<0.001)$, while the "onset of blood lactate accumulation" at 4 mmol $\mathrm{L}^{-1}$ occurred at later stages $(+24.4$ and $+19.8 \%$, both $P<0.01)$. At the same time points, ball accuracy at $100 \% \dot{V}_{2 \max }$ increased in $\mathrm{RSH}$ only $(+38.2 \%, P=0.003$ and $+40.9 \%, P=0.007$ ). Markers of TEST performance did not change for both RSN and CON. Compared to Pre, RSA total time increased significantly at Post-1 and Post-2 $(-1.9$ and $-2.5 \%, P<0.05)$ in $\mathrm{RSH}$ only and this was accompanied by larger absolute $\Delta$ total hemoglobin $(+82.5$ and $+137 \%$, both $P<0.001)$. HRV did not change either supine or standing positions.

Conclusion: Five repeated sprint training sessions in hypoxia using tennis specific shuttle runs improve physiological and technical responses to TEST, RSA, and accompanying muscle perfusion responses in well-trained tennis players.

Keywords: sport-specific fitness, hypoxia, repeated-sprint, tennis performance, repeated sprint ability, maximal aerobic exercise intensity

\section{INTRODUCTION}

Elite tennis players possess well-developed technical and tactical skills and high fitness level in order to cope with the physical demands of the game. They need to develop a combination of fitness qualities such as speed, agility, repeated sprint ability (RSA), power as well as high aerobic fitness (Reid and Schneiker, 2008). Optimizing training time remains challenging due to 
congested tennis competition calendars. Repeated-sprint exercise sessions, with the potential of concomitantly increasing maximal oxygen uptake $\left(\dot{\mathrm{VO}}_{2 \text { max }}\right)$ and speed/power during tests of RSA, represent effective means for physical performance enhancement in tennis (Bishop et al., 2011). Furthermore, it is believed that exercise training prescription should be as specific as possible to facilitate appropriate physiological adaptations (Reilly et al., 2009).

Although repeated-sprint exercise sessions are most frequently performed in normoxia (RSN), their completion in systemic hypoxia (RSH) is increasingly popular in many sports (e.g., soccer, rugby, cross-country skiing) since it can provide additional performance benefits. A recent meta-analysis indicated that mean power during repeated-sprint exercise is further enhanced with RSH compared to RSN (Brocherie et al., 2017a). Additional benefits of RSH have been reported in many intermittent sports including tennis (Faiss et al., 2013a). For example, single sprint time $(-4.5 \%)$, RSA total time $(-3.1 \%)$ and sprint decrement $(-16.7 \%)$ improved in one rookie tennis player during a stress test 3 weeks after undertaking a RSH intervention (Brechbuhl et al., 2018b). Well-trained tennis players also increased time to exhaustion and onset of blood lactate accumulation at $4 \mathrm{mMol} \mathrm{L}^{-1}$ as well as the ball accuracy $(+13.8 \%)$ immediately after five RSH sessions (Brechbuhl et al., 2018a).

To date, there is still scarce evidence about the acute and long-term responses to an on-court sport-specific RSH session (Brechbuhl et al., 2018b). With physical performance only acutely (within days) assessed after the RSH intervention, the longterm (few weeks) maintenance of its effects (if any) is currently unclear (Puype et al., 2013). To our knowledge it has never been investigated with ball hitting; so, a new adapted design is required to assess RSA for tennis players. Particularly, sprinting back and forth, as shown by Gatterer et al. (2015) in soccer players (but without ball hitting), would appear more appropriate than straight line used in previous studies with tennis players.

It was proposed that the effectiveness of RSH comes from an improved muscle blood perfusion, which in turn would benefit from optimized oxygen extraction by fast-twitch fibers (Faiss et al., 2013b). Since a previous study (Brechbuhl et al., 2018a) has reported that RSH can maintain a high level of accuracy at high levels of playing intensity, it would be of interest to investigate if cerebral as well as muscular blood flow could be increased using near infrared spectroscopy (NIRS).

Beyond the effects of RSH on physiological and performance parameters, the impact of this training method on the fatigue state has only been investigated acutely after one session in elite badminton players (Valenzuela et al., 2019). Heart rate variability (HRV) has been presented as a promising tool to differentiate fatigue states, and many studies have reported the influence of the training components on HRV due to a modulation in autonomic nervous system activity (Schmitt et al., 2006). One could speculate that RSH may lead to specific modifications of the neuro-vegetative system activity; e.g., an increase in sympathetic activity combined with a decrease in parasympathetic influence which may lead to a more prolonged state of fatigue (Lehmann et al., 1998). Ramos-Campo et al. (2017) found no differences in autonomic modulation after a high-intensity training session performed under hypoxic or normoxic conditions, but they did not measure the effects on the following days.

Using a double-blind controlled design, the present study aimed to investigate the immediate and prolonged effects of RSH vs. RSN using on-court tennis displacements, compared to control group (CON) on physical and technical tennis performance in well-trained players. We hypothesized that RSH would provide greater gains on RSA-related parameters than RSN as well as more favorable muscle oxygenation levels. We also postulated that $\mathrm{RSH}$ would induce a better resistance to fatigue in tennis-specific incremental test, observable mainly near exhaustion, concomitant with enhanced brain, and muscle perfusion measured during RSA and higher sympathetic activity in supine position.

\section{MATERIALS AND METHODS}

\section{Subjects}

Thirty-six competitive tennis players (27 males and 9 females) volunteered to participate in the study. They were all welltrained [i.e., international tennis number (ITN): 1 (elite) to 2 (advanced player)], allowing them to take part in a qualifying draw of International Tennis Federation (ITF) events $(n=24)$; some players were holding a professional (ATP) ranking $(n=3)$. Participants were first contacted by email to inform them of the project. Four of them declined after the medical examinations because they were running out of time or got ankle sprain just before the beginning of the physical testing. The group assignment was finalized during this period of inclusion by the main investigator. Our intention was also to match tennis level and age of our participants between the three groups (cf. Table 1). The sample size of our control group was smaller since these individuals likely had a lower risk of sustaining a musculoskeletal

TABLE 1 | Subjects characteristics.

\begin{tabular}{lccc}
\hline & RSH $(\boldsymbol{n}=\mathbf{1 1})$ & RSN $(\boldsymbol{n}=\mathbf{1 1})$ & Control $(\boldsymbol{n}=\mathbf{8})$ \\
\hline Age (year) & $25.7 \pm 6.8$ & $31.3 \pm 4.5$ & $29.6 \pm 5.1$ \\
& {$[21.1-30.3]$} & {$[27.0-32.6]$} & {$[25.3-33.9]$} \\
Height $(\mathrm{cm})^{\star *}$ & $179 \pm 5$ & $175 \pm 7$ & $\mathbf{1 8 5} \pm \mathbf{5}^{\star *}$ \\
& {$[176-182]$} & {$[169-179]$} & {$[\mathbf{1 8 1 - 1 8 9 ]}$} \\
Weight (kg) & $72.6 \pm 8.9$ & $69.5 \pm 8.7$ & $76.0 \pm 12.5$ \\
& {$[66.6-78.6]$} & {$[63.7-75.3]$} & {$[65.5-86.5]$} \\
VO$_{2 m a x}$ & $57.2 \pm 7.9$ & $57.8 \pm 5.6$ & $56.7 \pm 4.7$ \\
(mL min $\left.^{-1} \mathrm{~kg}^{-1}\right)$ & {$[52.0-62.4]$} & {$[54.0-61.6]$} & {$[51.4-61.0]$} \\
TTE (s) & $549 \pm 101$ & $621 \pm 113$ & $582 \pm 72$ \\
& {$[481-617]$} & {$[527-716]$} & {$[540-635]$} \\
RSA $_{T T}(\mathrm{~s})$ & $31.6 \pm 1.1$ & $32.5 \pm 2.0$ & $32.3 \pm 2.1$ \\
& {$[30.7-32.5]$} & {$[30.8-34.2]$} & {$[30.5-34.1]$} \\
National tennis & $1.9 \pm 2.5$ & $1.5 \pm 3.2$ & $1.0 \pm 2.9$ \\
ranking (a.u.) & {$[0.2-3.6]$} & {$[-0.8$ to 3.9] } & {$[-1.4$ to 3.4] } \\
\hline
\end{tabular}

Values are mean $\pm S D$ [95\% Cl]. Significant differences in the mean values among the groups.

${ }^{*} P P<0.01$ for Control players taller than those in the RSN group, in bold.

The equivalent national ranking [arbitrary units (a.u.)] is ranged from [-5] to [+19]; lower is the ranking, higher is the level of performance. 
injury compared to the two experimental groups performing repeated "all out" efforts. Two participants had to stop during the training period; one got a muscle injury and one felt a heart arrhythmia. Data of these individuals have been removed from final analysis. A priori power analysis using $\mathrm{G}^{*}$ Power software (version 3.1.9.3) was conducted to determine the appropriate sample size. Based on the data from a previous study (Brechbuhl et al., 2018a) on effects of repeated-sprints in hypoxia $(\sim 3000 \mathrm{~m})$ vs. normoxia, 27 participants overall were required to yield the targeted analysis power of $\beta=0.8$ at $\alpha=0.05$ for three groups and three measurements. To reach the appropriate sample size with potential risks of drop-out or injuries, the present sample was increased to $n=36$.

The information was disseminated to a list of players with the help of tennis coaches living in Paris and the surrounding region. Inclusion criteria were: (i) age between 18 and 35 years old; (ii) a ranking allowing players to take part in a national team championship; and (iii) no previous exposure to normobaric hypoxia in the past 6 months. Exclusion criteria were any history of altitude-related sickness or health risks that would have compromised the participant's safety during the experiment. They all have been screened by a sport cardiologist using echocardiography and blood testing. Participants gave their written informed consent after having been fully informed about the experimental procedure. The study was approved by the local ethical committees (French National Conference of Research Ethics Committees-Ile de France 6, No. 77-17) that was performed in accordance with the ethical standards reported (Harriss et al., 2017) and conformed to the recommendations of the Declaration of Helsinki.

\section{Study Design}

According to their competitive tennis level (known from their national ranking), gender and fitness level, participants were split into three groups: RSH ( $n=12 ; 9$ males and 3 females), RSN ( $n=12 ; 8$ males and 4 females), and $\operatorname{CON}(n=8 ; 7$ males and 1 female) (Table 1). Players in CON group continued their regular training routine throughout study. All participants in RSN and $\mathrm{RSH}$ groups undertook five additional training sessions across 12 days. Specifically, training sessions occurred on days 1, 3, 5, 9, and 11 for RSH and days 2, 4, 8, 10, and 12 for RSN. Physical and technical evaluations were performed for all tested players before (Pre-), immediately after (Post-1) and 3 weeks (Post-2) after Post1. The time of day for testing was controlled and matched both within and between groups.

\section{Specific Training Sessions}

All specific training sessions were performed in an airconditioned $\left(21^{\circ} \mathrm{C}\right)$ normobaric hypoxic room (size 15.04 $\mathrm{m} \times 8.54 \mathrm{~m}$; b-Cat ${ }^{\circledR}$, Netherlands). For RSH, the inspired fraction of oxygen $\left(\mathrm{FiO}_{2}\right)$ was set at $14.5 \%$, equivalent to a simulated altitude of $\sim 3,000 \mathrm{~m}$. Each session lasted $\sim 60 \mathrm{~min}$, including a 20 min warm-up phase, the repeated-sprint training routine, and a 10 min cooling-down phase (i.e., a total of $\sim 300$ min for the five sessions during the 12 days training period). Specifically, the repeated-sprint training routine included four sets of four maximal shuttle-run sprints of $\sim 8$ s [i.e., a sequence of two back and forth sprints that was concluded by hitting a ball to a retaining net] interspersed with $\sim 22 \mathrm{~s}$ of recovery (departing every $30 \mathrm{~s}$ ) (Figure 1). Balls were thrown manually by an investigator (the same during all the investigation) toward a target located on the floor at the time when the preceding ball was hit by the player (cf. Figure 1). Between each set, subjects were allowed a $4 \mathrm{~min}$ and $50 \mathrm{~s}$ passive rest period. Overall the subjects performed a total of 100 shuttle-runs during the 12 days intervention. A water fountain was on site to facilitate hydration during the resting periods.

Training loads [arbitrary units (a.u.)] were calculated for all subjects as the product of the total session duration (min) and RPE (Foster, 1998) for all training sessions during the experimental protocol including repeated sprints.

\section{Blinding}

This research was conducted in a double-blind, controlled manner. The blinding was carefully controlled (e.g., groups assignment, all materials' screens covered by a black tissue). For careful blinding purpose (see below), the hypoxic system was also running $\left(\mathrm{FiO}_{2} 20.9 \%\right.$ equivalent to $\left.\sim 200 \mathrm{~m}\right)$ for $\mathrm{RSN}$ sessions in order to create similar background noise. The efficacy of the blinding process was evaluated upon experiment termination (i.e., immediately after Post-2) by administering Likert scales (100 m marks from 0 to $4,000 \mathrm{~m}$ ), where each participant had to indicate (separately) which simulated altitude he/she believed he/she had been training in.

\section{Pre, Post-1, and Post-2 Testing Sessions}

A testing session lasted $2.5 \mathrm{~h}$. Participants were invited to arrive at the testing venue $30 \mathrm{~min}$ before their scheduled time for repeated sprint training session to test their HRV. One hour after the beginning of the sprints sessions, they completed on the technological court available at the French Tennis Federation a specific test with ball hitting (Brechbuhl et al., 2016a). We describe tests following the order used during the three measurement time points.

\section{HRV Analysis}

HRV was analyzed at arrival on site the day of tests. A detailed description of the protocol is available elsewhere (Schmitt et al., 2013). Briefly, the test lasted $14 \mathrm{~min}$ starting with $8 \mathrm{~min}$ in the supine position, followed by $6 \mathrm{~min}$ in the standing position. The periods analyzed were 3-8 $\mathrm{min}$ and 9-14 min, respectively, and were identical for all the subjects and all the tests. Measurement of the interval duration between two $\mathrm{R}$ waves of the cardiac electrical activity were performed using a Polar S810 heart rate (HR) monitor (Polar ${ }^{\circledR}$, Kempele, Finland), which has been validated by comparison with ECG measurements (Kingsley et al., 2005). The root mean square differences of successive heart beat intervals (RMSSD) was calculated as a measure of parasympathetic modulation (Task Force of the European Society of Cardiology and North American Society of Pacing and Electrophysiology, 1996). Then the spectral power was calculated with Fast Fourier Transform (FFT) by a specific software (Nevrokard ${ }^{\circledR}$ HRV, Medistar, Ljubljana, Slovenia). The spectral power was measured by frequency bands in $\mathrm{ms}^{2} \mathrm{~Hz}^{-1}$ : 
B
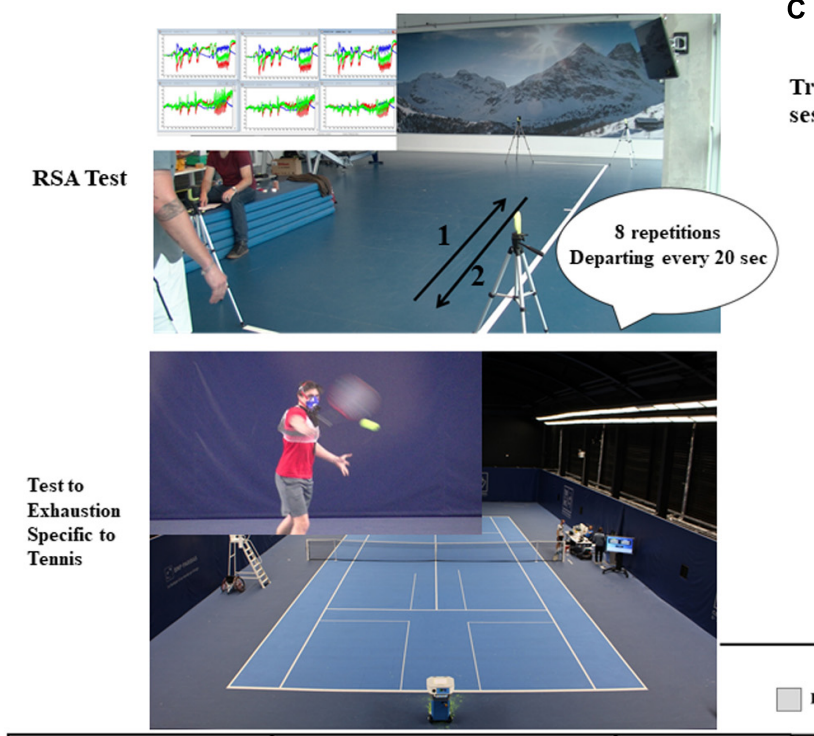

C
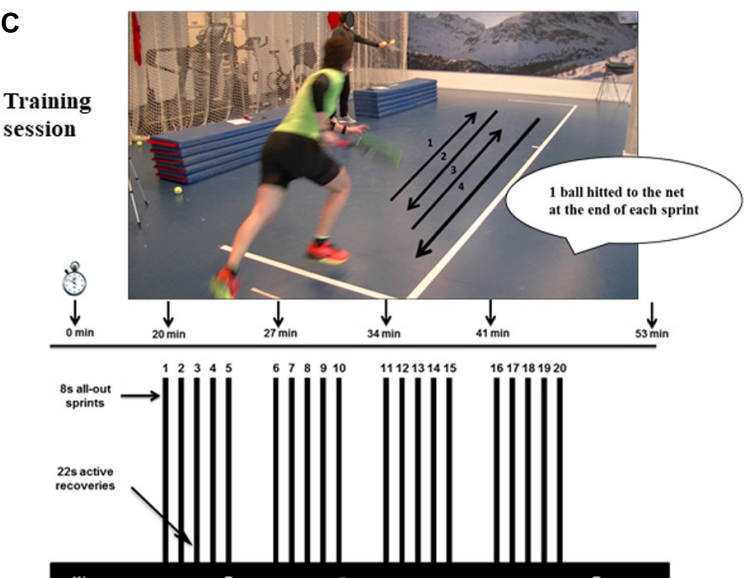

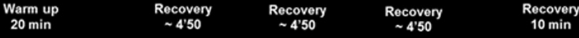

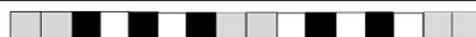

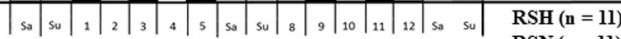

\begin{tabular}{ll} 
Day without intervention $\square$ RSH Day (blinded) $\square$ RSN Day (blinded) $\begin{array}{l}\operatorname{RSN}(n=11) \\
\text { Control }(n=8)\end{array}$ \\
\hline
\end{tabular}

phoning and/or individual

meeting

Heart Rate

Variability

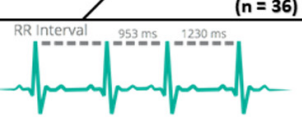

Medical Visit

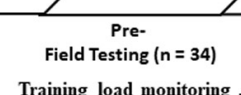

Week 2-3

Pid

\begin{tabular}{cc} 
Week 4 & Week 5-6 \\
$\begin{array}{c}\text { Post-1 } \\
\text { Field Testing } \\
(\mathrm{n}=30)\end{array}$ & $\begin{array}{c}\text { Post Intervention } \\
\text { Period }\end{array}$ \\
\hline
\end{tabular}

Week 7

FIGURE 1 | Protocol overview. General procedure (A), and description of a typical repeated-sprint training sessions, in normoxia (RSN) or hypoxia (RSH) (C). Field testing including repeated-sprint ability (RSA), Test to Exhaustion Specific to Tennis, heart rate variability (B), before the training intervention period (Pre-), during the week after (Post-1), and Post-2, 3 weeks after termination of Post-1.

0.05-0.15 Hz: low frequency (LF) reflecting predominantly the sympathetic system influence and in relationship with the arterial blood pressure.

0.15-0.40 Hz: high frequency (HF) reflecting the parasympathetic system influence and in relationship with the respiratory rate.

\section{Repeated Sprints}

The RSA test consisted of eight shuttle-run sprints (Figure 1) departing every $20 \mathrm{~s}$, with passive recovery between efforts [adapted from a previous running test that has been shown to be reliable and valid in estimating RSA (Buchheit et al., 2010)]. Each sprint was initiated from a standing position, $50 \mathrm{~cm}$ behind the photocell gate, which started a digital timer. Sprint times were measured to the nearest $0.01 \mathrm{~s}$ using photocells connected to an electronic timer (Witty, Microgate ${ }^{\circledR}$, Bolzano, Italy), whose height was adjusted according to the height of the subject's hip. During the first sprint, subjects were required to achieve at least 95\% of their criterion score (i.e., defined as the best of three single back and forth sprints with 2 min of recovery) as a check of any pacing strategy. This measure was realized at the end of a warm-up. All of the subjects satisfied this criterion score. Three seconds before the start of each point, participants were asked to assume the ready position and to await the start signal with a countdown (“3, 2, 1, go"). Three scores were calculated from the RSA test: best sprint time ( $\left.\mathrm{RSA}_{\text {best }}\right)$, total sprint time $\left(\mathrm{RSA}_{\mathrm{TT}}\right)$ and percentage of sprint decrement $\left(\mathrm{S}_{\mathrm{dec}}\right)$ determined as $\left[\mathrm{RSA}_{\mathrm{TT}} /\left(\mathrm{RSA}_{\text {best }} \times 8\right)-1\right] \times 100$ (Girard et al., 2011).
Maximal lactate concentration (La) $\max$ was measured 3 min after the last sprint.

\section{Specific Aerobic Capacity}

After $40 \mathrm{~min}$ of rest, subjects performed an incremental field test up to exhaustion [i.e., the so-called test to exhaustion specific to tennis (TEST)] as detailed previously (Brechbuhl et al., 2016a, 2018a). Briefly, TEST consisted of hitting balls thrown by a "Hightof" ${ }^{\circledR}$ ball machine at constant velocity. Both accuracy and reliability of the machine have been previously reported and appears relevant for field testing and training purposes (Brechbuhl et al., 2016b). Subjects had to hit balls cross-court in a prescribed pattern (i.e., topspin drive), while the landing point for thrown balls was set $3 \mathrm{~m}$ in front of baseline (Brechbuhl et al., 2016a). The first TEST stage begun with a ball frequency $(\mathrm{BF})$ of 10 shots $\mathrm{min}^{-1}$, thereafter increased by +2 shots $\min ^{-1}$ every minute until the stage corresponding to a $\mathrm{BF}$ of 22 shots $\mathrm{min}^{-1}$. From there, increment in BF was set at +1 shots $\min ^{-1}$ until exhaustion (Brechbuhl et al., 2016a). After each $1 \mathrm{~min}$ stage, a $30 \mathrm{~s}$ passive recovery break (quiet standing) was implemented.

\section{Evaluation of Groundstroke Performance}

During TEST, groundstroke production was assessed by the mean of two "primary" variables: ball velocity (BV) and ball accuracy (BA). BV $\left(\mathrm{km} \mathrm{h}^{-1}\right)$ was measured with the Playsight ${ }^{\circledR}$ system (Israël), which has been approved by the ITF as a tennis player analysis technology for all ITF-sanctioned tournaments. All shots 
that were hit out, into the net, and to the wrong spot on the tennis court were excluded. BA (\%) was defined as the percentage of correct hits in the defined zones. For each stage, BV and BA data were averaged. Finally, because $\mathrm{BV}_{\text {mean }}$ and $\mathrm{BA}_{\text {mean }}$ better reflect the overall stroke precision in tennis when combined, a $\mathrm{TP}_{\text {mean }}$ index was calculated as the product of these two variables. Calculation of overall mean values was based on the values obtained for each stage. We considered technical parameters at $100 \% \dot{\mathrm{VO}}_{2 \max }$ with at least 20 balls hit during the stage $\left(\mathrm{BV}_{\max }\right.$, $\left.\mathrm{BA}_{\max }, \mathrm{TP}_{\text {max }}\right)$.

\section{Physiological Measurements}

During TEST, HR (Suunto Ambit $2^{\circledR}$, Vantaa, Finland) and expired air were analyzed continuously (breath-by-breath measurements) for oxygen consumption $\left(\dot{\mathrm{VO}}_{2}\right)$ using a portable gaz analyzer (Metamax II CPX system, Cortex ${ }^{\circledR}$, Leipzig, Germany). Gas and volume calibration of the measurement device were performed before each test according to manufacturer' instructions. Furthermore, $25 \mu \mathrm{l}$ capillary blood samples were taken from fingertip and analyzed for (La) (LT-1710, Arkray ${ }^{\circledR}$, Japan) at baseline, during TEST (i.e., during the $30 \mathrm{~s}$ recovery periods after every stage until a values of $4 \mathrm{mmol} \mathrm{L}^{-1}$ was obtained and thereafter every second stages) and $15 \mathrm{~s}$ after exhaustion. $\dot{\mathrm{VO}}_{2 \max }$ was determined by the observation of a "plateau" or leveling off in $\dot{\mathrm{VO}}_{2}$ or when the increase in two successive periods was less than $150 \mathrm{~mL} \mathrm{~min}{ }^{-1}$ (Wasserman et al., 2005). The maximal lactate concentration $(\mathrm{La})_{\max }$ were also recorded at the end of TEST.

Detection of ventilatory thresholds (VTs) was achieved by identifying points of breakdown in linearity based on ventilatory parameters. The first ventilatory threshold (VT1) was determined using the criteria of an increase in the ventilatory equivalent for oxygen $\left(\dot{\mathrm{VE}} / \mathrm{V}_{2}\right)$ with no increase in the ventilatory equivalent for carbon dioxide $\left(\dot{\mathrm{VE}} / \mathrm{V} \mathrm{CO}_{2}\right)$ and departure from the linearity of $\dot{\mathrm{VE}}$ caused by a more rapid increase in ventilation. VT2 corresponded to an increase in both $\dot{\mathrm{VE}} / \mathrm{V}_{2}$ and $\dot{\mathrm{VE}} / \mathrm{VCCO}_{2}$ (Wasserman et al., 2005). All VTs assessments were made by visual inspection of graphs of time plotted against each relevant respiratory variable measured during testing. All visual inspections were carried out by two experienced exercise physiologists. The results were then compared and averaged. The difference in the individual determinations of VT2 was $<3 \%$.

The "onset of blood lactate accumulation" (OBLA), defined as the exercise intensity corresponding to $4 \mathrm{mmol} \mathrm{L}^{-1}$ blood lactate concentration was also determined. By plotting each subject's blood lactate concentration against time of TEST completion and visually connecting the data points, we estimated the time to attain OBLA. This physiological variable has been shown to be a good predictor of endurance performance (Bentley et al., 2007).

\section{Near-Infrared Spectroscopy Measurements}

Tissue oxygenation was evaluated using the NIRS technique as described previously by Boushel and Piantadosi (2000). The PortaMon and PortaLite devices (Artinis ${ }^{\circledR}$, Zetten, Netherlands) were used during the RSA test to measure muscle oxygenation of the vastus lateralis (PortaMon) and of the prefrontal cortex (PortaLite) at wavelengths between 760 and $850 \mathrm{~nm}$, respectively. All devices were placed into a tight transparent plastic wrap to avoid humidity and create a waterproof barrier for proper function and signal quality. The PortaMon was placed on the lower third of the vastus lateralis and attached with double sided tape, then wrapped with tension against the leg to reduce movement during exercise. The position was marked with a permanent pen and images were taken to reproduce the placement in subsequent visits. The PortaLite was attached on the surface of the left prefrontal cortex with double sided tape, then the subject was fitted with a head wrap to create a dark environment and maintain a stable position of the probe. Measurements included a standard differential pathlength factor of 4.0 for the vastus lateralis as there is a lack of any clear standard value for the quadriceps (Faiss et al., 2013b) and 6.0 for the prefrontal cortex, similar to Amann et al. (2007). All signals were recorded at the maximum frequency for each device $(10 \mathrm{~Hz}$ for PortaMon and $50 \mathrm{~Hz}$ for PortaLite) and then exported at $10 \mathrm{~Hz}$ for further analysis (Oxysoft 3.0.53, Artinis, Netherlands). For analysis, a 4th-order low-pass zero-phase Butterworth filter (cutoff frequency $0.2 \mathrm{~Hz}$ ) was implemented to reduce artifacts and smooth perturbations in the signal from pedal strokes. All data (except absolute TSI) was normalized to the last $30 \mathrm{~s}$ of the seated resting baseline. Because concentrations for deoxyhemoglobin $(\mathrm{HHb})$ values were proposed to be less sensitive to blood flow variations than oxyhemoglobin $\left(\mathrm{O}_{2} \mathrm{Hb}\right)$ and changes in $\mathrm{O}_{2} \mathrm{Hb}$ signals might be confounded by rapid blood volume changes during sprints (Buchheit et al., 2009), only $(\mathrm{HHb})$ and total hemoglobin/myoglobin $(\mathrm{tHb})$ were analyzed for relevant interpretations. Differences between maximum and minimum concentrations were defined as the amplitude of the variation for each sprint $[\Delta(\mathrm{tHb})$ and $\Delta(\mathrm{HHb})]$, and $\Delta(\mathrm{tHb})$ was used as an index of blood perfusion (Faiss et al., 2013b). Thus, for example, at the beginning of each sprint, a maximum in $(\mathrm{tHb})$ is observed (i.e., end of each recovery period) and ( $\mathrm{tHb})$ decreases to reach a minimum value at the end of each sprint. As well, the absolute maximum tissue saturation index (TSI, $\%$ ) was obtained from each sprint. This allowed determination of successive sprint and recovery phases to be identified, and sprint phases to be further analyzed. The mean change $(\Delta)$ for the eight sprints was defined as the mean difference between maximum and minimum values for the overall repeated sprints series. Mean delta absolute tissue saturation index (Absolute $\Delta$ TSI, \%), total hemoglobin/myoglobin [Absolute $\Delta(\mathrm{tHb})$ ], and concentrations of deoxyhemoglobin $[\Delta(\mathrm{HHb})]$ were obtained for muscle (from vastus lateralis) and cerebral oxygenation (from prefrontal cortex).

\section{Statistical Analysis}

All data are expressed as the mean \pm SD. Mean difference for change between Pre- and Post-1 or Post-2 (expressed as $\%$ ), and 95\% confidence interval (95\% CI) were reported when appropriate. One-way ANOVA was used to test differences in training load and initial participants' characteristics between groups. Two-way repeated measures ANOVA [Time ( Pre-, Post1 vs. Post-2) $\times$ Group (RSH, RSN vs. Control)] analysis was 
applied to compare performance and physiological variables. Pairwise differences were identified using the Tukey post hoc analysis procedure adjusted for multiple comparisons. For each two-way repeated measures ANOVA and each pairwise differences, effect sizes were calculated with Cohen's d (d) with the following criteria: a $\mathrm{d}$ of $<0.2$ is classified as a trivial, $0.2-0.4$ as a small, $0.5-0.7$ as a moderate and $>0.8$ as a large effect (Hopkins et al., 2009). Pearson's product moment correlation analysis was employed to determine the relationships within and between technical parameters and TTE relative changes, as between TTE and time to attain OBLA. The following criteria was adopted to interpret the magnitude of $r$ : $<0.1$, trivial; $0.1-0.3$, small; $0.3-0.5$, moderate; $0.5-0.7$, large; $0.7-0.9$, very large; and 0.9-1.0, almost perfect (Hopkins et al., 2009). The null hypothesis was rejected at $P<0.05$. Statistical analysis was performed using Sigmaplot 3.5 software (Systat Software, San Jose, CA).

Because of missing data, a linear mixed model has been used for repeated sprint NIRS results. Changes in tissues oxygenation during the RSA test were evaluated with a linear mixed model three-way repeated-measures analysis of variance (ANOVA) (time $\times$ group $\times$ sprint number). Fixed effects were time (Pre-, Post-1, Post-2), group (CON, RSN, RSH) and the sprint number (1-8), whereas subjects were considered as the random effect. Analyses were performed using R (R Core team 2017, Foundation for Statistical Computing, Vienna, Austria).

\section{RESULTS}

\section{Efficacy of the Blinding Procedure}

Participants indicated not different simulated altitude of $1882 \mathrm{~m}$ (95\% CI: 1,273-2,491 m, range, 0-3,000 m) and $1591 \mathrm{~m}$ (95\% CI: 769-2,413 m, range, 0-4,000 m) for RSH and RSN, respectively. This indicates that the blinding process was successful and that subjects were unaware of the condition group classification.

\section{Training Load}

Overall training load was closely matched among RSH $(11,179$ a.u, 95\% CI: 7,074-15,284 a.u), RSN (8,366 a.u, 95\% CI: 4,70712,025 a.u) and CON: 11,678 a.u, 95\% CI: 5,024-18,331 a.u) groups $(P=0.403)$. No difference in mean training load occurred between Pre- and Post-1 (RSH: 5,006 a.u, 95\% CI: 2,709-7,302 a.u; RSN: 3,838 a.u, 95\% CI: 1,753-5,923 a.u; CON: 5,688 a.u, 95\% CI: 2,732-8,644 a.u.; $P=0.478$ ), and between Post-1 and Post-2 (RSH: 6,173 a.u, 95\% CI: 4,027-8,319 a.u; RSN: 4,528 a.u, 95\% CI: 2,316-6,740 a.u; CON: 5,990 a.u, 95\% CI: 2,131-9,849 a.u., $P=0.458)$ across groups.

\section{Aerobic Capacity}

There was a significant interaction between time and group for TTE $\left(P=0.002, \eta_{p}^{2}=0.05\right)$. Post hoc analysis revealed that, compared to Pre, TTE increased at Post-1 $(+18.3 \%, P<0.001$, $\mathrm{d}=0.97)$ and Post $-2(+17.3 \%, P<0.001, \mathrm{~d}=0.97)$ in $\mathrm{RSH}$, with no change in RSN and CON. Physiological responses to on-court endurance testing are summarized in Table 2.

Time to VT2 after the training period increased significantly only in RSH at Post-1 $(+19.4 \%, P=0.004, \mathrm{~d}=0.06)$ and Post-2
$(+26.9 \%, P<0.001, \mathrm{~d}=1.16)$ in reference to Pre. Concomitant changes in time to attain OBLA at Post-1 $(+24.4 \%, P<0.001$, $\mathrm{d}=0.78)$ and Post $-2(+19.8 \%, P=0.003, \mathrm{~d}=0.84)$ vs. Pre were observed for RSH only. Significant moderate correlation in time to attain OBLA and TTE relative changes was observed $(r=0.60$, $P<0.0001)$, when Post- 1 and Post- 2 are considered vs. Pre.

\section{Technical Parameters}

There was a main time effect for $\mathrm{BV}_{\text {mean }}\left(P<0.001 ; \eta_{p}{ }^{2}=0.05\right)$ but not for $\mathrm{TP}_{\text {mean }}\left(P=0.29, \eta_{p}^{2}=0.01\right)$ (Figures $2 \mathrm{~A}, \mathrm{C}$ ).

Compared to Pre, $\mathrm{BA}_{\max }$ at $100 \% \dot{\mathrm{VO}}_{2 \max }$ increased in $\mathrm{RSH}$ at Post-1 (+38.2\%, 95\% CI: $1.0-48.4 \%, P=0.003, \mathrm{~d}=0.44)$ and Post-2 (+40.9\%, 95\% CI: $+5.0-45.9 \%, P=0.007, \mathrm{~d}=0.53)$ (Figure 2E). There was a significant increase in $\mathrm{BV}_{\max }$ for RSN at Post-2 (+8.7\%, 95\% CI: $+1.5-15.9 \%, P=0.007, \mathrm{~d}=0.96)$. Increases in $\mathrm{TP}_{\max }$ for $\mathrm{RSH}$ occurred at Post-1 (+41.4\%, 95\% CI: $0-51.6 \%, P=0.006, \mathrm{~d}=0.87)$ and Post $-2(+46.3 \%, 95 \% \mathrm{CI}$ : $2.5-47.8 \%, P=0.003, \mathrm{~d}=1.00)$ compared to Pre (Figure 2F).

Significant small to large correlations were found between $\mathrm{TP}_{\text {mean }}$ and TTE $(r=0.32, P=0.01)$, and between changes in $\mathrm{BA}_{\text {mean }}$ throughout the whole test and TTE $(r=0.53, P<0.0001)$. $\mathrm{TP}_{\text {mean }}$ changes are largely correlated with those obtained in $\mathrm{BA}_{\text {mean }}(r=0.89, P<0.0001)$ when the three groups are pooled.

\section{Sprint-Performance Parameters}

A time effect was found for $\operatorname{RSA}_{\text {best }}(P=0.004 ; \mathrm{d}=0.24)$ and $\operatorname{RSA}_{\mathrm{TT}}(P<0.001 ; \mathrm{d}=0.21)$ A (Table 3). Compared with Pre-, RSH decreased RSA best at Post-1 (-2.6\%, 95\% CI: -6.2 to $+1.0 \%, P=0.018, \mathrm{~d}=0.63)$ and $\mathrm{RSA}_{\mathrm{TT}}(-1.9 \%, 95 \% \mathrm{CI}$ : -5.1 to $+1.3 \%, P=0.027, \mathrm{~d}=0.52)$, and Post $-2(-5.1 \%, 95 \%$ CI: -8.7 to $-1.5 \%, P<0.001, \mathrm{~d}=0.50$, and $-2.5 \%, 95 \% \mathrm{CI}$ : -5.8 to $+0.7 \%, 95 \%: P=0.021, \mathrm{~d}=0.17$, for $\mathrm{RSA}_{\text {best }}$ and $\mathrm{RSA}_{\mathrm{TT}}$, respectively). RSN also improved $\mathrm{RSA}_{\mathrm{TT}}$ in the same proportion at Post-1 $(P=0.002)$ and Post-2 $(P=0.004)(-1.0 \%, 95 \% \mathrm{CI}$ : -8.2 to $+3.2 \%, \mathrm{~d}=0.2$ ), while $\mathrm{RSA}_{\text {best }}$ did not differ. $\mathrm{S}_{\mathrm{dec}}$ did not change significantly.

The maximal blood lactate concentration (values for all groups compounded) remained unchanged between Pre-(9.7 \pm 2.5 mMol L $\left.{ }^{-1}\right)$, Post-1 $\left(8.7 \pm 3.8 \mathrm{mMol} \mathrm{L}^{-1}\right)$ and Post-2 $(8.2 \pm 5.4$ $\left.\mathrm{mMol} \mathrm{L}^{-1}\right)(P=0.421, \mathrm{~d}=0.2)$.

\section{Peripheral Oxygenation}

As indicated in Figure 3, there was an interaction between group and time for the absolute maximal TSI (TSImax). of the vastus lateralis Post hoc analysis indicated a lower absolute (TSImax) values at Post-1 for $\operatorname{RSN}(-3.6 \%, 95 \% \mathrm{CI}:-5.7$ to $-1.5 \%$, $P<0.001, \mathrm{~d}=1.53)$ in reference to Pre followed by a significant increase between Post-1 and Post-2 (+2.7\%, 95\% CI: 0.8-4.6\%, $P=0.003, \mathrm{~d}=1.26)$.

RSH increased the absolute $\Delta(\mathrm{tHb})$ from Pre- to Post-1 (+82.6\%, 95\% CI: -94 to $248 \%, P<0.001, \mathrm{~d}=0.45)$. There was a further increase from Post-1 to Post-2 for RSH; we had a significant change from Pre- $(+137 \%, 95 \%$ CI: -20 to $293 \%$, $P<0.001, \mathrm{~d}=0.78)$, differently than other groups. A main effect of time was observed when Post-2 was compared with Post-1 $(F=6.49, P=0.01)$, but there was no main effect of group (Figure $3 \mathbf{B}$ ). 
TABLE 2 | Performance and physiological responses to TEST before (Pre-), after the repeated sprint training in hypoxia (RSH) and normoxia (RSN) interventions or in the control group the week after (Post-1) and 3 weeks after Post-1 (Post-2).

\begin{tabular}{|c|c|c|c|c|c|c|c|c|c|c|c|c|}
\hline & \multicolumn{3}{|c|}{ RSH } & \multicolumn{3}{|c|}{ RSN } & \multicolumn{3}{|c|}{ Control } & \multicolumn{3}{|c|}{ ANOVA (d) } \\
\hline & Pre- & Post-1 & Post-2 & Pre- & Post-1 & Post-2 & Pre- & Post-1 & Post-2 & Time & Condition & Interaction \\
\hline TTE (s) & $\begin{array}{l}549 \pm 101 \\
{[481-617]}\end{array}$ & $\begin{array}{c}649 \pm 105^{\star} \\
{[578-720]}\end{array}$ & $\begin{array}{c}643 \pm 95^{\star \star} \\
{[583-704]}\end{array}$ & $\begin{array}{l}582 \pm 72 \\
{[534-630}\end{array}$ & $\begin{array}{l}582 \pm 94 \\
{[519-646]}\end{array}$ & $\begin{array}{l}605 \pm 82 \\
{[558-684]}\end{array}$ & $\begin{array}{l}621 \pm 113 \\
{[527-716]}\end{array}$ & $\begin{array}{l}615 \pm 90 \\
{[540-689]}\end{array}$ & $\begin{array}{l}604 \pm 112 \\
{[523-685]}\end{array}$ & $0.008(0.32)$ & $0.926(0.12)$ & $0.002(0.45)$ \\
\hline $\begin{array}{l}\dot{\mathrm{VO}} \mathrm{Vmax}_{2} \\
\left(\mathrm{~mL} \mathrm{~min}^{-1} \mathrm{~kg}^{-1}\right)\end{array}$ & $\begin{array}{l}57.2 \pm 7.8 \\
{[52.0-62.4]}\end{array}$ & $\begin{array}{l}58.7 \pm 7.0 \\
{[54.0-63.4]}\end{array}$ & $\begin{array}{c}58.5 \pm 7.5 \\
{[53.7-63.3]}\end{array}$ & $\begin{array}{l}57.9 \pm 6.0 \\
{[54.0-61.6]}\end{array}$ & $\begin{array}{l}57.3 \pm 6.2 \\
{[53.1-61.5]}\end{array}$ & $\begin{array}{l}59.0 \pm 7.0 \\
{[54.4-63.2]}\end{array}$ & $\begin{array}{l}56.2 \pm 5.7 \\
{[51.4-61.0]}\end{array}$ & $\begin{array}{l}56.3 \pm 6.1 \\
{[51.2-61.4]}\end{array}$ & $\begin{array}{l}57.0 \pm 6.8 \\
{[51.3-62.7]}\end{array}$ & $0.131(0.13)$ & $0.839(0.21)$ & $0.116(0.11)$ \\
\hline $\begin{array}{l}\mathrm{HR}_{\max } \\
\text { (beats } \min ^{-1} \text { ) }\end{array}$ & $\begin{array}{c}190 \pm 8 \\
{[185-195]}\end{array}$ & $\begin{array}{c}191 \pm 5 \\
{[188-195]}\end{array}$ & $\begin{array}{c}193 \pm 6 \\
{[189-197]}\end{array}$ & $\begin{array}{c}190 \pm 7 \\
{[186-195]}\end{array}$ & $\begin{array}{c}191 \pm 8 \\
{[186-197]}\end{array}$ & $\begin{array}{c}191 \pm 8 \\
{[185-196]}\end{array}$ & $\begin{array}{c}190 \pm 9 \\
{[182-198]}\end{array}$ & $\begin{array}{c}190 \pm 8 \\
{[183-197]}\end{array}$ & $\begin{array}{c}190 \pm 8 \\
{[181-200}\end{array}$ & $0.231(0.15)$ & $0.902(0.16)$ & $0.115(0.12)$ \\
\hline$\dot{V} E_{\max }\left(L \min ^{-1}\right)$ & $\begin{array}{l}124 \pm 19 \\
{[112-137]}\end{array}$ & $\begin{array}{c}130 \pm 17 \\
{[119-141.6]}\end{array}$ & $\begin{array}{l}133 \pm 19 \\
{[120-145]}\end{array}$ & $\begin{array}{l}123 \pm 11 \\
{[116-130]}\end{array}$ & $\begin{array}{l}124 \pm 15 \\
{[114-143]}\end{array}$ & $\begin{array}{l}126 \pm 17 \\
{[115-137]}\end{array}$ & $\begin{array}{l}132 \pm 20 \\
{[116-149]}\end{array}$ & $\begin{array}{l}132 \pm 24 \\
{[112-152]}\end{array}$ & $\begin{array}{c}128 \pm 19 \\
{[117-139]}\end{array}$ & $0.607(0.13)$ & $0.472(0.35)$ & $0.473(0.24)$ \\
\hline $\begin{array}{l}{[\mathrm{La}]_{\max }} \\
\left(\mathrm{mMol} \mathrm{L}{ }^{-1}\right)\end{array}$ & $\begin{array}{l}10.9 \pm 4.1 \\
{[8.1-13.7]}\end{array}$ & $\begin{array}{l}9.7 \pm 3.6 \\
{[7.3-12.1]}\end{array}$ & $\begin{array}{l}11.2 \pm 5.2 \\
{[7.9-14.5]}\end{array}$ & $\begin{array}{l}8.8 \pm 3.1 \\
{[6.7-10.9]}\end{array}$ & $\begin{array}{l}8.8 \pm 2.9 \\
{[6.9-10.7]}\end{array}$ & $\begin{array}{c}7.2 \pm 2.3 \text { * } \\
{[5.7-8.7]}\end{array}$ & $\begin{array}{l}9.0 \pm 1.7 \\
{[7.6-10.4]}\end{array}$ & $\begin{array}{l}8.5 \pm 2.7 \\
{[6.2-10.8]}\end{array}$ & $\begin{array}{l}10.3 \pm 4.7 \\
{[7.9-12.7]}\end{array}$ & $0.494(0.14)$ & $0.284(0.46)$ & $0.04(0.39)$ \\
\hline Time to OBLA (s) & $\begin{array}{l}374 \pm 98 \\
{[306-439]}\end{array}$ & $\begin{array}{c}465 \pm 118^{\star \star \star} \\
{[384-543]}\end{array}$ & $\begin{array}{c}447 \pm 108^{\star \star} \\
{[378-516]}\end{array}$ & $\begin{array}{l}409 \pm 92 \\
{[351-468]}\end{array}$ & $\begin{array}{l}414 \pm 111 \\
{[339-489]}\end{array}$ & $\begin{array}{l}451 \pm 82 \\
{[399-504]}\end{array}$ & $\begin{array}{l}405 \pm 77 \\
{[341-469]}\end{array}$ & $\begin{array}{l}435 \pm 77 \\
{[371-499]}\end{array}$ & $\begin{array}{l}420 \pm 82 \\
{[382-458]}\end{array}$ & $0.001(2.56)$ & $0.970(0.07)$ & $0.097(0.31)$ \\
\hline Time to VT1 (s) & $\begin{array}{l}228 \pm 114 \\
{[134-322]}\end{array}$ & $\begin{array}{c}288 \pm 120 \text { * } \\
{[210-366]}\end{array}$ & $\begin{array}{c}312 \pm 108^{*} \\
{[240-384]}\end{array}$ & $\begin{array}{c}228 \pm 48 \\
{[196-260]}\end{array}$ & $\begin{array}{l}234 \pm 54 \\
{[198-270]}\end{array}$ & $\begin{array}{l}234 \pm 90 \\
{[204-264]}\end{array}$ & $\begin{array}{l}204 \pm 78 \\
{[137-268]}\end{array}$ & $\begin{array}{l}228 \pm 60 \\
{[186-270]}\end{array}$ & $\begin{array}{l}234 \pm 42 \\
{[159-309]}\end{array}$ & $0.019(0.32)$ & $0.191(0.56)$ & $0.142(0.29)$ \\
\hline$\% \mathrm{HR}_{\max }$ at $\mathrm{VT} 1$ & $\begin{array}{l}93.8 \pm 2.5 \\
{[92.1-95.5]}\end{array}$ & $\begin{array}{c}92.2 \pm 2.9 * * \\
{[90.2-94.1]}\end{array}$ & $\begin{array}{c}92.5 \pm 2.6 \\
{[90.8-95.3]}\end{array}$ & $\begin{array}{l}92.1 \pm 5.5 \\
{[88.4-95.8]}\end{array}$ & $\begin{array}{l}90.1 \pm 3.5^{\star} \\
{[87.8-92.4]}\end{array}$ & $\begin{array}{l}89.2 \pm 4.4 \\
{[86.2-92.2]}\end{array}$ & $\begin{array}{c}91.0 \pm 4.8 \\
{[87.0-95.0]}\end{array}$ & $\begin{array}{l}87.8 \pm 4.1 \\
{[84.4-91.2]}\end{array}$ & $\begin{array}{c}88.5 \pm 4.8 \\
{[84.5-92.5]}\end{array}$ & $0.003(0.44)$ & $0.090(0.70)$ & $0.401(0.21)$ \\
\hline Time to VT2 (s) & $\begin{array}{l}402 \pm 102 \\
{[336-468]}\end{array}$ & $\begin{array}{c}480 \pm 90^{\star *} \\
{[420-540]}\end{array}$ & $\begin{array}{c}510 \pm 84^{\star \star \star} \\
{[456-564]}\end{array}$ & $\begin{array}{l}420 \pm 96 \\
{[354-486]}\end{array}$ & $\begin{array}{l}408 \pm 108 \\
{[336-480]}\end{array}$ & $\begin{array}{l}420 \pm 96 \\
{[354-486]}\end{array}$ & $\begin{array}{l}480 \pm 90 \\
{[414-546]}\end{array}$ & $\begin{array}{l}444 \pm 72 \\
{[383-502]}\end{array}$ & $\begin{array}{l}474 \pm 84 \\
{[402-546]}\end{array}$ & $0.077(0.26)$ & $0.784(0.21)$ & $0.004(0.48)$ \\
\hline$\% \mathrm{HR}_{\max }$ at $\mathrm{VT} 2$ & $\begin{array}{l}98.4 \pm 1.1 \\
{[97.6-99.4]}\end{array}$ & $\begin{array}{l}98.2 \pm 1.2 * \\
{[97.4-99.0]}\end{array}$ & $\begin{array}{l}98.1 \pm 1.3^{*} \\
{[97.2-99.0]}\end{array}$ & $\begin{array}{l}98.8 \pm 1.3 \\
{[97.7-99.9]}\end{array}$ & $\begin{array}{c}96.6 \pm 2.0^{\star \star} \\
{[95.3-97.9]}\end{array}$ & $\begin{array}{l}96.8 \pm 1.7 \\
{[95.7-97.9]}\end{array}$ & $\begin{array}{l}98.5 \pm 1.3 \\
{[97.7-99.1]}\end{array}$ & $\begin{array}{l}97.2 \pm 2.0 \text { * } \\
{[95.5-98.9]}\end{array}$ & $\begin{array}{l}97.6 \pm 1.4 \text { * } \\
{[96.4-98.7]}\end{array}$ & $<0.001(0.58)$ & $0.053(0.61)$ & $0.167(0.34)$ \\
\hline
\end{tabular}

Values are mean \pm SD [95\% CI]. Significant differences from baseline (Pre-) to the end of the intervention period (Post-1) and 3 weeks after Post-1 (Post-2).

${ }^{*} P<0.05,{ }^{* *} P<0.01,{ }^{* * *} P<0.001$ are in bold. Statistical Analysis is based on absolute values. Cohen's $d$ (d) were calculated as measures of effect sizes for two-way repeated measures ANOVA.

$T T E$, total time to exhaustion; $V^{2} \mathrm{~V}_{2 m a x}$, maximal oxygen uptake; HRmax, maximal heart rate; $V E_{\max }$, maximal ventilation; [La] max, maximal lactate concentration; OBLA, onset of blood lactate accumulation, at 4 mMol $L^{-1}$,

VT1, first ventilatory threshold; VT2, second ventilatory threshold. Note that Time to VT1 and time to VT2 only consider time of practice excluding rest between stages and specific warm-up. 

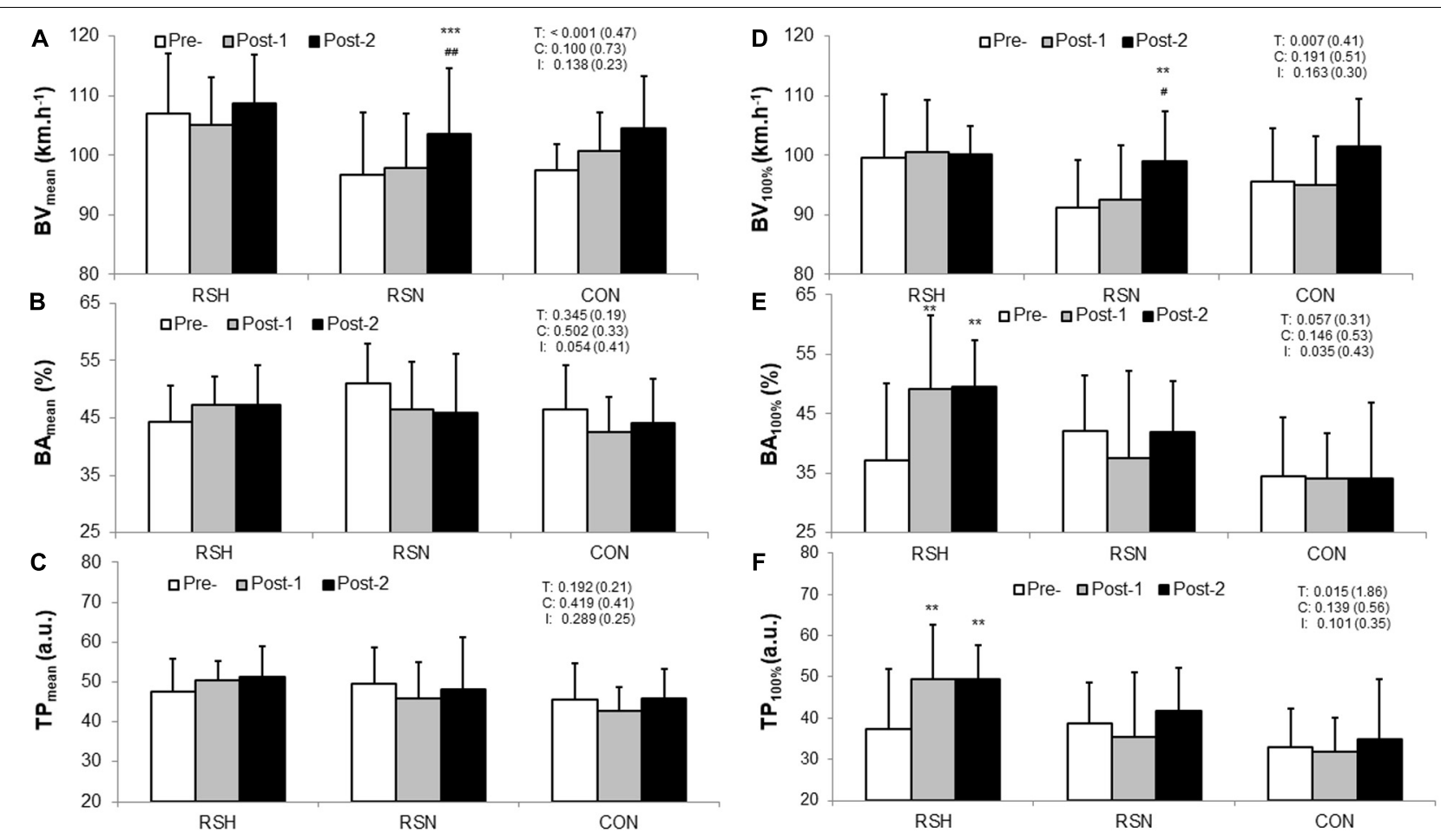

FIGURE 2 | Comparison of the technical performance within and between type of intervention (RSH vs. RSN vs. CON). Representation of the overall technical performance index $\left(\mathrm{TP}_{\text {mean }}, \mathbf{C}\right)$ is calculated as the product of the ball velocity $\left(\mathrm{BV}_{\text {mean }}, \mathbf{A}\right)$ and the ball accuracy $\left(B A_{\text {mean }}, \mathbf{B}\right)$ during the test to exhaustion specific to tennis. Data of the overall test are confronted to those at $100 \% \dot{V}_{2 m a x}$ : $B V_{\max }$ (D), BA $A_{\max }$ (E), TP max (F). TP is expressed in arbitrary units (a.u.). Values are Mean $\pm S D$. BA is calculated as a percentage of balls in a defined zone (\%). T, C, and I denote ANOVA main effects of time, group and interaction between these two factors with $P$-value and Cohen's d (d) into brackets. ${ }^{\star \star \star} P<0.001$, ${ }^{\star \star} P<0.01$ significantly different from Pre-. ${ }^{\# \#} P<0.01$, ${ }^{\#} P<0.05$ significantly different from Post-1.

A group $\mathrm{x}$ time interaction was found for $\Delta(\mathrm{HHb})(F=4.4$, $P=0.03$ ) but no main effects of time and group.

\section{Cerebral Oxygenation}

The level of cerebral oxygenation [absolute TSImax (\%)] was higher in RSN with a significant increase from Pre to Post$1(+7.8 \%, P<0.0001)$, and from Pre to Post-2 $(+8.1 \%$, $P<0.0001)$. There was a significant interaction between time and group $(F=28.02, P=0.0001)$ but no main effect of group.

We obtained a significant interaction for absolute $\Delta$ (thb) $(F=11.74, P=0.0017)$. There was a significant effect of time $(P<0.001)$ for $\mathrm{tHb}$, with post hoc analysis indicating significantly higher values at both Post-1 et Post-2 vs. Pre, but no effect of group existed (Figure 3E).

\section{HRV}

There was no significant time and interaction effect for $\mathrm{HR}$ ( $P=0.289, \mathrm{~d}=0.17, P=0.347, \mathrm{~d}=0.23$, respectively, in supine position; and $P=0.899, \mathrm{~d}=0.06, P=0.401, \mathrm{~d}=0.25$, respectively, in standing position).

No significant time and interaction effect was observed for time-domain (RMSSD) $(P=0.424, \mathrm{~d}=0.42, P=0.683, \mathrm{~d}=0.36$, respectively, in supine position; and $P=0.249, \mathrm{~d}=0.53, P=0.351$, $\mathrm{d}=0.27$, respectively, in standing position). No significant time and interaction effect was found for spectral analysis (HF, LF) in either supine $(P=0.797, \mathrm{~d}=0.08, P=0.136, \mathrm{~d}=0.37$, for $\mathrm{LF}$; $P=0.728, \mathrm{~d}=0.09, P=0.185, \mathrm{~d}=0.18$, for $\mathrm{HF}$, respectively), or standing positions $(P=0.371, \mathrm{~d}=0.45, P=0.351, \mathrm{~d}=0.11$, for $\mathrm{LF}$; $P=0.722, \mathrm{~d}=0.13, P=0.832, \mathrm{~d}=0.05$, for $\mathrm{HF}$, respectively).

\section{DISCUSSION}

To the best of our knowledge, this is the first study examining the short-term (during the week after intervention) and prolonged effects ( 3 weeks after Post-1) of a hypoxic vs. normoxic specific training intervention designed for competitive tennis players. In partial agreement with our initial hypothesis, the main finding of this study was that a 12 days RSH intervention induced larger benefits for improving tennis-specific physical, physiological, and technical parameters than RSN and CON.

\section{Performance and Physiological Measurements}

The repeated-sprint training had a positive effect on RSA parameters for both training groups with an improvement in $\mathrm{RSA}_{\mathrm{TT}}$ for RSH $(-1.9$ and $-2.5 \%$, respectively), and RSN $(-1.2 \%$ at the two time points) at Post- 1 and Post- 2 in reference to Pre-, yet only RSH improved $\mathrm{RSA}_{\text {best }}$ ( -2.6 and $-5.1 \%$, respectively). These findings confirm the hypothesis that repeated sprint 


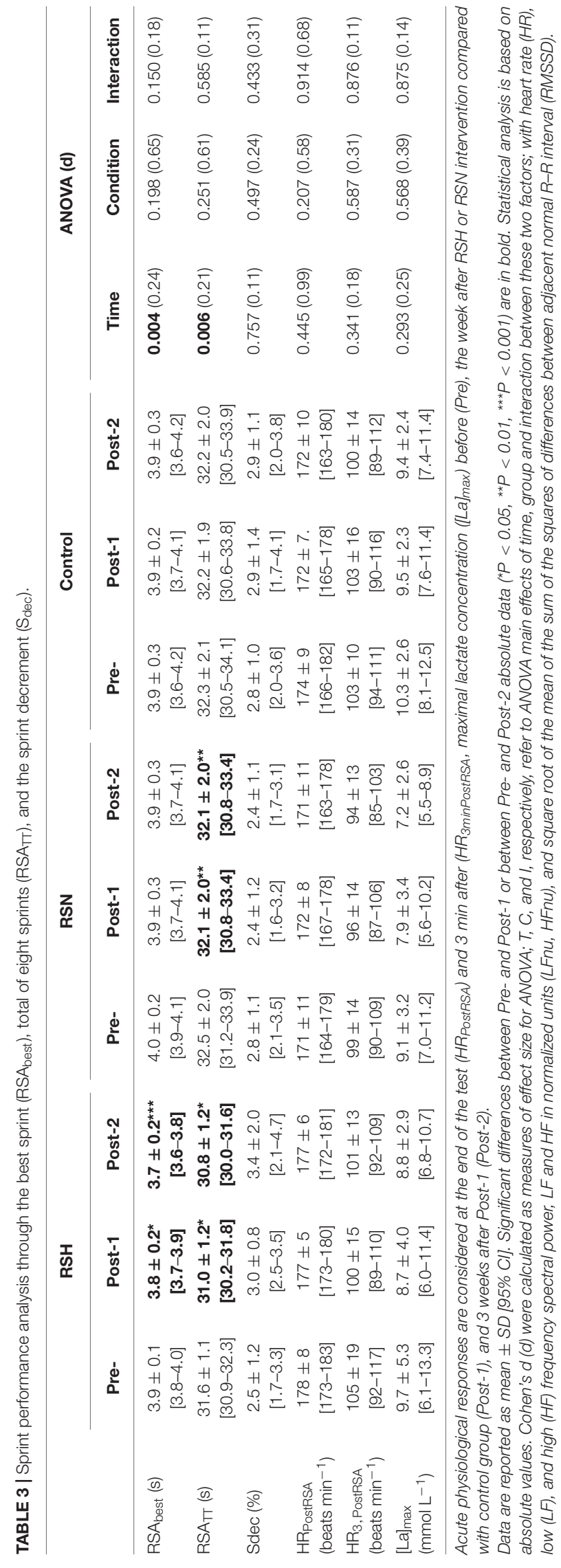

training ameliorates RSA, with larger benefits when conducted in hypoxia. We observed that RSH would induce beneficial adaptations mainly due to the improved blood perfusion level [absolute $\Delta(\mathrm{tHb})+82.6 \%$ at Post- $1,+137 \%$ at Post-2] inducing an enhanced oxygen utilization in legs (Figure 3). The present results, however, differ from previous ones from our research group (Brechbuhl et al., 2018a), who did not report any putative effect of hypoxia on RSA parameters. Although the training protocol was similar (though without the balls hits), the RSA test consisted of $20 \mathrm{~m}$ sprints without any direction change. Given that the protocol entailed $16.46 \mathrm{~m}$ (i.e., two lengths of a tennis court baseline) sprints with $180^{\circ}$ rotation in the middle, it could be argued that subjects developed more the neuromuscular qualities part of the sprint than maximal sprinting speed. Moreover, it has been reported in highly trained young soccer players that during a $40 \mathrm{~m}$ sprint, maximal speed was attained between the 30 and the $40 \mathrm{~m}$ distance mark (Buchheit et al., 2012). The fact that the present RSA test was more tennis-specific could explain the discrepancy in RSA results despite a similar protocol and tested population. Given that elite players on average run $3 \mathrm{~m}$ per shot and change four times directions during a point in official matches (FernandezFernandez et al., 2009), their maximal sprinting speed will most probably never be reached. On the other hand, they will need to constantly accelerate, decelerate and reaccelerate for effective stroke production. If the participants did indeed develop deceleration and reacceleration capabilities, regardless of maximal sprinting speed, it would still be particularly relevant for improving tennis-specific performance.

In the present study, we found that RSH delayed fatigue during TEST and increased TTE $(+18.3 \%$ at Post- 1 and $17.3 \%$ at Post2), whereas RSN and CON had no change. These observations confirm previous results obtained with tennis players when RSH was only compared to RSN during the first week immediately after intervention $(+14.6 \%$ for $\mathrm{RSH}$ vs. $+7.9 \%$ for $\mathrm{RSN})$ (Brechbuhl et al., 2018a). In the present study, this improvement cannot be explained by a better absolute aerobic power since there was no change in $\dot{\mathrm{V}}_{2 \max }$ or other ventilation parameters. Interestingly, the augmented time to attain OBLA suggest that toward the end of TEST, RSH spend a similar amount of time at severe exercise intensities; while the time when that particular intensity was reached occurred later. This finding is in accordance with Brechbuhl et al. (2018a), who found an increased TTE, as well as time to VT2 and time to OBLA in a similar protocol that did not incorporated actual ball hitting during training sessions. Therefore, RSH increased submaximal workload intensity for a same blood lactate concentration. A rookie professional tennis player also improved his Yo-Yo intermittent recovery test level 2 ( $+21 \%$ distance covered, 21 days after the training intervention) (Brechbuhl et al., 2018b). Of interest is that this beneficial effect of RSH on TTE was larger in upper-body exercise (i.e., doublepoling sprint training in hypoxia) (Faiss et al., 2015). As with this study, our results showed higher improvement with balls hitting compared with previous findings based on sprints only (Brechbuhl et al., 2018a).

The variables time to attain OBLA and time of VT2 occurrence in $\mathrm{RSH}$ that correlated with endurance performance have been 

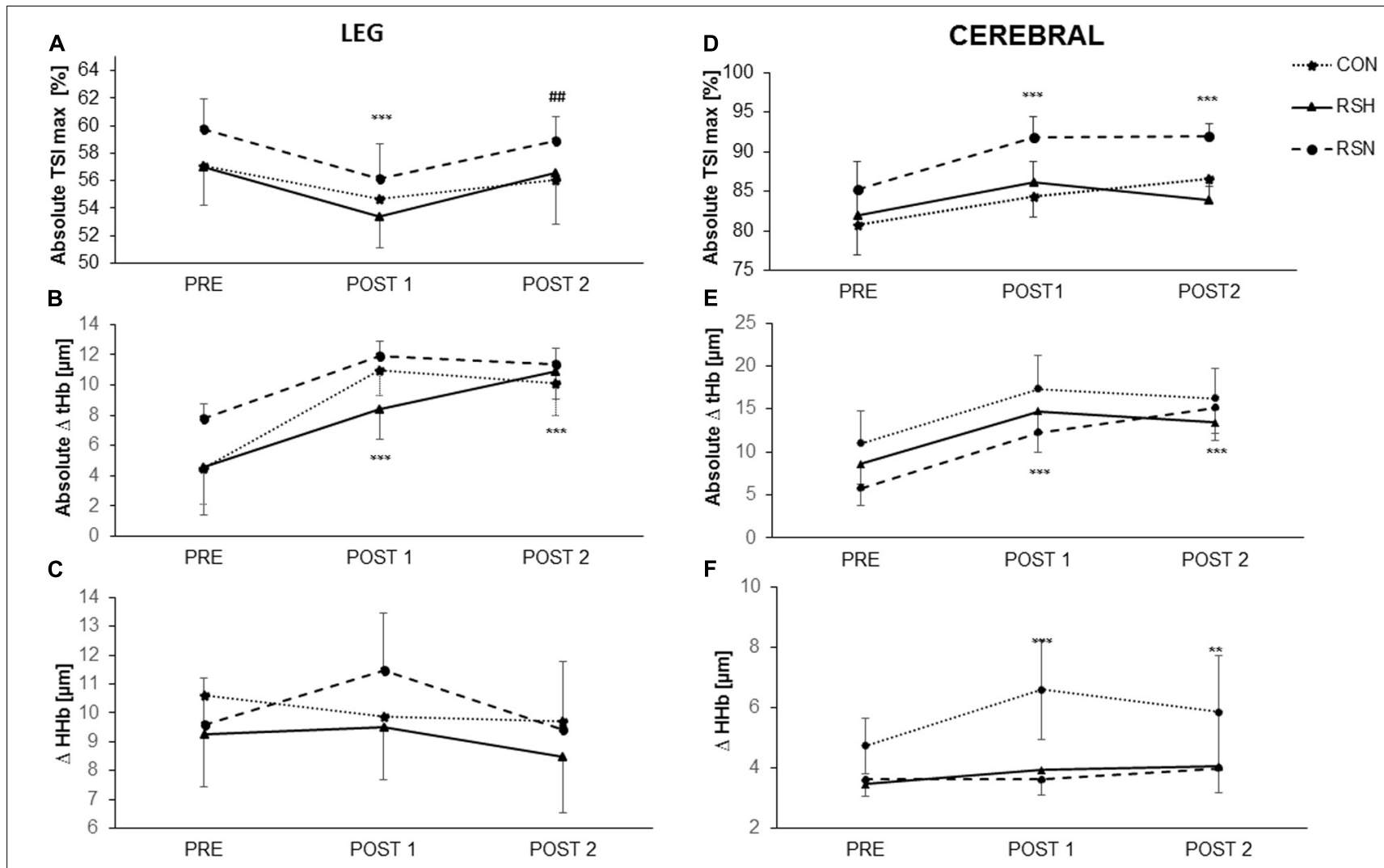

FIGURE 3 | Representation of oxygenation parameters in vastus lateralis (leg) (A-C) and prefrontal cortex (cerebral) (D-F) during the test of repeated sprint ability. Maximal tissue saturation (\%) [Absolute TSImax (\%)] for leg (A) and cerebral (D); Differences between maximum and minimum concentrations of total hemoglobin/myoglobin (Absolute $\Delta \mathrm{tHb}$ ) for leg (B) and cerebral (E); Differences between maximum and minimum concentrations of deoxyhemoglobin ( $\Delta \mathrm{HHb})$. For leg (C) and cerebral (F). ${ }^{\star \star} P<0.001,{ }^{\star \star} P<0.01$ significant main effect in time, different from PRE. \#\# $P<0.01$ significant main effect in time, different from Post-1.

used to prescribe exercise training loads and are useful to monitor adaptation to training (Bentley et al., 2007). It has been previously demonstrated that cycling power output corresponding to OBLA improved by $+7 \%$ during an incremental test after $\mathrm{RSH}$ only immediately after intervention (Puype et al., 2013). This is in line with the enhanced buffer capacity or upregulation of genes involved in $\mathrm{pH}$ control previously reported after $\mathrm{RSH}$ (Faiss et al., 2013b; Puype et al., 2013). This improvement in VT2 is of practical importance since it has been prioritized to be a better marker of submaximal endurance performance than $\dot{\mathrm{V}}_{2 \max }$. Reportedly, VT2 is correlated with competitive level in male tennis player $(r=0.55 ; P=0.001)$ (Baiget et al., 2014). According to Konig et al. (2001), high VT values could reflect the ability to tolerate high exercise intensity during tennis competitions. Additionally, our study shows that RSH was the only group to improve the time to VT1 (Table 2).

Based on our overall present results, we can speculate that physiological adaptations would likely explain improvements in time to attain OBLA, time to VT2 and TTE in the RSH group. While $\mathrm{VO}_{2 \max }$ did not improve post-training (Figure 2), time to attain OBLA, time to VT2 and TTE increased at Post-1 $(+24.4$, +19.4 , and $+18.3 \%$, respectively), and Post-2 $(+19.8,+26.9$, and $+17.3 \%$, respectively). During the RSA test, we report that $\mathrm{RSH}$ had beneficial adaptations concomitant with the improved blood perfusion level in their legs [absolute $\Delta(\mathrm{tHb})+82.6 \%$ at Post- $1,+137 \%$ at Post-2, Figure 3] inducing an enhanced oxygen utilization. With maximal effort intensities, specific skeletal muscle adaptations (molecular level) may arise through the oxygen-sensing pathway (i.e., capillary-to-fiber ratio, fiber cross-sectional area, myoglobin content, and oxidative enzyme activity such as citrate synthase) that either do not occur in RSN or, if they do, they do so to a lesser degree (Zoll et al., 2006; Faiss et al., 2013a). As exercising in hypoxia is known to trigger a compensatory vasodilatation to match an increased oxygen demand at the muscular level (Casey and Joyner, 2012), hypoxic and maximal effort intensity are combined to increase the training stimulus. However, unchanged $\dot{\mathrm{VO}}_{2 \max }$ values may be explained by the unchanged cardiac output which could be measured in future study.

\section{Fatigue and HRV}

An interesting and novel finding of the present study was the lack of differences between groups and time points in markers of autonomic fatigue. This observation is not in line with previous responses to altitude training ("Living high-training low" paradigm) that remain complex since hypoxia and training stresses are combined (Schmitt et al., 2006). In hypoxia, the reduced inspired pressure of oxygen represents an additional 
stress, which has been shown to alter the autonomous regulation of the nervous system (Schmitt et al., 2006). Responses in HRV are subsequently with a combination of increased sympathetic and decreased parasympathetic nervous activities (Schmitt et al., 2006). A recent study showed also that HRV returned to basal values the day following a RSH session, which suggests that the exercise performed did not elicit long-lasting effects in autonomic modulation (Valenzuela et al., 2019). It also confirms previous psychophysiological responses to repeated sprints training. Despite higher hypoxia-induced physiological and perceptual strain during the first session, perceptual responses improved thereafter in RSH so as not to differ from RSN (Brocherie et al., 2017b). This already indicated an effective acclimation and tolerance to this innovative training.

\section{Technical Performance Measurements}

The $\mathrm{TP}_{\max }$ enhancement of the $\mathrm{RSH}$ group (Figure $2 \mathbf{F}$ ) during TEST were mainly related to improved $\mathrm{BA}_{\max }$ (Figure $2 \mathrm{E}$ ) and cannot be explained by a lack of involvement in ball hitting in favor of lower energy consumption. We did not find significant differences in $\mathrm{BV}_{\text {mean }}$ (Figure $2 \mathrm{~A}$ ) between $\mathrm{RSH}$ and the other two groups from Pre- to Post-tests as it was the case for $\mathrm{BV}_{\max }$ at $100 \% \dot{\mathrm{VO}}_{2 \max }$ (Figure 2D). Moreover, the level of engagement in strokes is also confirmed by the exhaustion criteria (i.e., $\mathrm{VE}_{\max }$, $\mathrm{HR}_{\text {max }}$ ) that were similar in both groups (Table 2).

$\mathrm{BA}_{\max }$ significantly increased in $\mathrm{RSH}$, whereas it decreased slightly in RSN and did not differ in CON (Figure 2E). While a potential learning effect, due to unchanged data obtained by $\mathrm{CON}$, cannot be ruled out it seems that fatigue resistance was improved for $\mathrm{RSH}$, which may potentially be transferable to technical performance gains. However, few investigations conducted on cognitive skills (e.g., visual search and decision making) in hypobaric or normobaric hypoxic conditions have demonstrated their acute effects on attention, perception, executive functioning and short-term memory (Mcmorris et al., 2017). Our study does not confirm potential effect on cerebral oxygenation kinetics following $\mathrm{RSH}$ intervention to explain why this training group had higher accuracy scores near exhaustion (Brechbuhl et al., 2018a). For practical reasons NIRS evaluation was only conducted during RSA test so that evaluation of technical performance during TEST would not be disturbed.

\section{Practical Applications}

With the modern tennis game becoming increasingly dynamic and tournament schedules more demanding, adapted strategy to improve or maintain physical fitness are needed (Reid and Schneiker, 2008). In this context, additional adaptations by using upper body (e.g., with ball hitting) during RSH with its positive influence on RSA and muscle blood perfusion (Faiss et al., 2015) appear more suitable than extending the length of protocol. RSH is an effective short-term intervention to develop and maintain tennis-specific capabilities to maximize fitness when players are involved in a series of 3-4 consecutive tournaments. We propose that this intervention can be programmed 2-3 times per season in order to develop or maintain the athletes' aerobic capacity and BA. Indeed, five sessions of RSH spread over 12 days could trigger adaptations beneficial for both sprinting and tennisspecific performance with no additional fatigue.

\section{Limitations and Perspectives}

Despite being tested in ecological situation, players were wearing a portable analyzer (additional weight of $\sim 0.7 \mathrm{~kg}$ ), while the mask might have also affected vision. However, it is important to note that all players during both Pre- and Post- Tests sessions wore this equipment, so any potential negative effect (i.e., earlier fatigue due to extra weight to carry or impaired accuracy due to perturbations in vision) would have been similar in all situations. We acknowledge that it is important to use valid and reliable test procedures, also including tests of RSA. Despite the large number of tests of RSA available in the literature, no gold standard procedure existing for the purpose of testing tennis players on this fitness component. Tennis Australia recommends a test including $10 \times 20 \mathrm{~m}$ straight-line sprints with $20 \mathrm{~s}$ rest (Fernandez-Fernandez et al., 2014). A more tennis-specific test, including $10 \times \sim 20 \mathrm{~m}$ shuttle sprints was also implemented with tennis players (Fernandez-Fernandez et al., 2012). When testing RSA it is crucial to avoid occurrence of pacing and so short and tennis specific drill are important characteristics of the test selected. Importantly, we also familiarized our participants with this testing procedure before pre-tests to exclude any learning effects.

\section{CONCLUSION}

Five RSH sessions over 12 days is an efficient strategy for causing larger immediate improvements in tennis-specific anaerobic, aerobic, and technical performance compared to RSN and a control group. Practically, RSH also benefited oncourt technical performance, particularly the ball accuracy near exhaustion $\left(100 \% \dot{\mathrm{VO}}_{2 \mathrm{max}}\right)$. Improved repeated-sprint ability was accompanied by increases in marker of blood perfusion. In addition, markers of autonomic modulation remained largely unaffected under the conditions of the present study.

Unique was also the fact that most of these aforementioned gains are maintained at least 4 weeks in the RSH group only.

\section{DATA AVAILABILITY STATEMENT}

The raw data supporting the conclusions of this article will be made available by the authors, without undue reservation.

\section{ETHICS STATEMENT}

The studies involving human participants were reviewed and approved by French National Conference of Research Ethics Committees-Ile de France 6, No. 77-17. The patients/participants provided their written informed consent to participate in this study. 


\section{AUTHOR CONTRIBUTIONS}

$\mathrm{CB}, \mathrm{LS}, \mathrm{GM}$, and $\mathrm{BM}$ conceived and designed the experiments. $\mathrm{CB}, \mathrm{FB}, \mathrm{LS}, \mathrm{TB}$, and $\mathrm{BM}$ performed the experiments. $\mathrm{CB}$, LS, GM, TB, and SW analyzed the data. CB, LS, TB, SW,

\section{REFERENCES}

Amann, M., Romer, L. M., Subudhi, A. W., Pegelow, D. F., and Dempsey, J. A. (2007). Severity of arterial hypoxaemia humans affects the relative contributions of peripheral muscle fatigue to exercise performance in healthy. J. Physiol. 581, 389-403. doi: 10.1113/jphysiol.2007.129700

Baiget, E., Fernandez-Fernandez, J., Iglesias, X., Vallejo, L., and Rodriguez, F. A. (2014). On-court endurance and performance testing in competitive male tennis players. J. Strength Cond. Res. 28, 256-264. doi: 10.1519/jsc. 0b013e3182955dad

Bentley, D. J., Newell, J., and Bishop, D. (2007). Incremental exercise test design and analysis: implications for performance diagnostics in endurance athletes. Sports Med. 37, 575-586. doi: 10.2165/00007256-200737070-00002

Bishop, D., Girard, O., and Mendez-Villanueva, A. (2011). Repeated-sprint ability - part II: recommendations for training. Sports Med. 41, 741-756. doi: 10.2165/ 11590560-000000000-00000

Boushel, R., and Piantadosi, C. A. (2000). Near-infrared spectroscopy for monitoring muscle oxygenation. Acta Physiol. Scand. 168, 615-622. doi: 10. 1046/j.1365-201x.2000.00713.x

Brechbuhl, C., Brocherie, F., Millet, G. P., and Schmitt, L. (2018a). Effects of Repeated-Sprint Training in Hypoxia on Tennis-Specific Performance in WellTrained Players. Sports Med. Int. Open 2, E123-E132.

Brechbuhl, C., Girard, O., Millet, G. P., and Schmitt, L. (2016a). On the Use of a Test to Exhaustion Specific to Tennis (TEST) with Ball Hitting by Elite Players. PLoS One 11:e0152389. doi: 10.1371/journal.pone.0152389

Brechbuhl, C., Millet, G. P., and Schmitt, L. (2016b). Accuracy and Reliability of a New Tennis Ball Machine. J. Sports Sci. Med. 15, 263-267.

Brechbuhl, C., Schmitt, L., Millet, G. P., and Brocherie, F. (2018b). Shock microcycle of repeated-sprint training in hypoxia and tennis performance: Case study in a rookie professional player. Int. J. Sports Sci. Coach 13, 723-728. doi: $10.1177 / 1747954118783586$

Brocherie, F., Girard, O., Faiss, R., and Millet, G. P. (2017a). Effects of RepeatedSprint Training in Hypoxia on Sea-Level Performance: A Meta-Analysis. Sports Med. 47, 1651-1660. doi: 10.1007/s40279-017-0685-3

Brocherie, F., Millet, G. P., and Girard, O. (2017b). Psychophysiological Responses to Repeated-Sprint Training in Normobaric Hypoxia and Normoxia. Int. J. Sports Physiol. Perform. 12, 115-123. doi: 10.1123/ijspp.2016-0052

Buchheit, M., Cormie, P., Abbiss, C. R., Ahmaidi, S., Nosaka, K. K., and Laursen, P. B. (2009). Muscle deoxygenation during repeated sprint running: Effect of active vs. passive recovery. Int. J. Sports Med. 30, 418-425. doi: 10.1055/s-00281105933

Buchheit, M., Mendez-Villanueva, A., Delhomel, G., Brughelli, M., and Ahmaidi, S. (2010). Improving repeated sprint ability in young elite soccer players: repeated shuttle sprints vs. explosive strength training. J. Strength Cond. Res. 24, 2715-2722. doi: 10.1519/jsc.0b013e3181bf0223

Buchheit, M., Simpson, B. M., Peltola, E., and Mendez-Villanueva, A. (2012). Assessing maximal sprinting speed in highly trained young soccer players. Int. J. Sports Physiol. Perform. 7, 76-78. doi: 10.1123/ijspp.7.1.76

Casey, D. P., and Joyner, M. J. (2012). Compensatory vasodilatation during hypoxic exercise: mechanisms responsible for matching oxygen supply to demand. J. Physiol. 590, 6321-6326. doi: 10.1113/jphysiol.2012.242396

Faiss, R., Girard, O., and Millet, G. P. (2013a). Advancing hypoxic training in team sports: from intermittent hypoxic training to repeated sprint training in hypoxia. Br. J. Sports Med. 47(Suppl. 1), i45-i50.

Faiss, R., Leger, B., Vesin, J. M., Fournier, P. E., Eggel, Y., Deriaz, O., et al. (2013b). Significant molecular and systemic adaptations after repeated sprint training in hypoxia. PLoS One 8:e56522. doi: 10.1371/journal.pone.0056522

Faiss, R., Willis, S., Born, D. P., Sperlich, B., Vesin, J. M., Holmberg, H. C., et al. (2015). Repeated double-poling sprint training in hypoxia by competitive and $\mathrm{FB}$ contributed reagents, materials, and analysis tools. $\mathrm{CB}$ and LS wrote the manuscript. $\mathrm{CB}, \mathrm{OG}, \mathrm{GM}, \mathrm{LS}$, and $\mathrm{FB}$ critical revision of the manuscript for important intellectual content. All authors contributed to the article and approved the submitted version.

cross-country skiers. Med. Sci. Sports Exerc. 47, 809-817. doi: 10.1249/mss. 0000000000000464

Fernandez-Fernandez, J., Sanz-Rivas, D., and Mendez-Villanueva, A. (2009). A Review of the Activity Profile and Physiological Demands of Tennis Match Play. Strength Condition. Res. 31, 15-26. doi: 10.1519/ssc.0b013e3181 ada $1 \mathrm{cb}$

Fernandez-Fernandez, J., Ulbricht, A., and Ferrauti, A. (2014). Fitness testing of tennis players: how valuable is it? Br. J. Sports Med. 48(Suppl. 1), i22-i31.

Fernandez-Fernandez, J., Zimek, R., Wiewelhove, T., and Ferrauti, A. (2012). Highintensity interval training vs. repeated-sprint training in tennis. J. Strength Cond. Res. 26, 53-62. doi: 10.1519/jsc.0b013e318220b4ff

Foster, C. (1998). Monitoring training in athletes with reference to overtraining syndrome. Med. Sci. Sports Exerc. 30, 1164-1168. doi: 10.1097/00005768199807000-00023

Gatterer, H., Klarod, K., Heinrich, D., Schlemmer, P., Dilitz, S., and Burtscher, M. (2015). Effects of a 12-day maximal shuttle-run shock microcycle in hypoxia on soccer specific performance and oxidative stress. Appl. Physiol. Nutr. Metab 40, 842-845. doi: 10.1139/apnm-2014-0479

Girard, O., Mendez-Villanueva, A., and Bishop, D. (2011). Repeated-sprint ability - part I: factors contributing to fatigue. Sports Med. 41, 673-694. doi: 10.2165/ 11590550-000000000-00000

Harriss, D. J., Macsween, A., and Atkinson, G. (2017). Standards for Ethics in Sport and Exercise Science Research: 2018 Update. Int. J. Sports Med. 38, 1126-1131. doi: 10.1055/s-0043-124001

Hopkins, W. G., Marshall, S. W., Batterham, A. M., and Hanin, J. (2009). Progressive statistics for studies in sports medicine and exercise science. Med. Sci. Sports Exerc. 41, 3-13. doi: 10.1249/mss.0b013e31818cb278

Kingsley, M., Lewis, M. J., and Marson, R. E. (2005). Comparison of Polar 810s and an ambulatory ECG system for RR interval measurement during progressive exercise. Int. J. Sports Med. 26, 39-44. doi: 10.1055/s-2004-817878

Konig, D., Huonker, M., Schmid, A., Halle, M., Berg, A., and Keul, J. (2001). Cardiovascular, metabolic, and hormonal parameters in professional tennis players. Med. Sci. Sports Exerc. 33, 654-658. doi: 10.1097/00005768-20010400000022

Lehmann, M., Foster, C., Dickhuth, H. H., and Gastmann, U. (1998). Autonomic imbalance hypothesis and overtraining syndrome. Med. Sci. Sports Exerc. 30, 1140-1145. doi: 10.1097/00005768-199807000-00019

Mcmorris, T., Hale, B. J., Barwood, M., Costello, J., and Corbett, J. (2017). Effect of acute hypoxia on cognition: A systematic review and meta-regression analysis. Neurosci. Biobehav. Rev. 74, 225-232. doi: 10.1016/j.neubiorev.2017. 01.019

Puype, J., Van Proeyen, K., Raymackers, J. M., Deldicque, L., and Hespel, P. (2013). Sprint interval training in hypoxia stimulates glycolytic enzyme activity. Med. Sci. Sports Exerc. 45, 2166-2174. doi: 10.1249/mss.0b013e31829734ae

Ramos-Campo, D. J., Rubio-Arias, J. A., Freitas, T. T., Camacho, A., JimenezDiaz, J. F., and Alcaraz, P. E. (2017). Acute Physiological and Performance Responses to High-Intensity Resistance Circuit Training in Hypoxic and Normoxic Conditions. J. Strength Cond. Res. 31, 1040-1047. doi: 10.1519/jsc. 0000000000001572

Reid, M., and Schneiker, K. (2008). Strength and conditioning in tennis: current research and practice. J. Sci. Med. Sport 11, 248-256. doi: 10.1016/j.jsams.2007. 05.002

Reilly, T., Morris, T., and Whyte, G. (2009). The specificity of training prescription and physiological assessment: a review. J. Sports Sci. 27, 575-589. doi: 10.1080/ 02640410902729741

Schmitt, L., Hellard, P., Millet, G. P., Roels, B., Richalet, J. P., and Fouillot, J. P. (2006). Heart rate variability and performance at two different altitudes in well-trained swimmers. Int. J. Sports Med. 27, 226-231. doi: 10.1055/s-2005865647 
Schmitt, L., Regnard, J., Desmarets, M., Mauny, F., Mourot, L., Fouillot, J. P., et al. (2013). Fatigue shifts and scatters heart rate variability in elite endurance athletes. PLoS One 8:e71588. doi: 10.1371/journal.pone.0071588

Task Force of the European Society of Cardiology and North American Society of Pacing and Electrophysiology (1996). Heart rate variability: standards of measurement, physiological interpretation and clinical use. Circulation 93, 1043-1065. doi: 10.1161/01.cir.93.5.1043

Valenzuela, P. L., Sanchez-Martinez, G., Torrontegi, E., Vazquez-Carrion, J., Gonzalez, M., Montalvo, Z., et al. (2019). Acute Responses to On-Court Repeated-Sprint Training Performed With Blood Flow Restriction Versus Systemic Hypoxia in Elite Badminton Athletes. Int. J. Sports Physiol. Perform. 14, 1280-1287. doi: 10.1123/ijspp.2018-0878

Wasserman, K. H. J., Sue, D., Stringer, W., Sietsema, K., Sun, X. G., and Whipp, B. J. (2005). Principles of Exercise Testing and Interpretation: Including Pathophysiology and Clinical Applications. Philadelphia, PA: Lippincott Williams \& Wilkins, 1-585.
Zoll, J., Ponsot, E., Dufour, S., Doutreleau, S., Ventura-Clapier, R., Vogt, M., et al. (2006). Exercise training in normobaric hypoxia in endurance runners. III. Muscular adjustments of selected gene transcripts. J. Appl. Physiol. 100, 1258-1266. doi: 10.1152/japplphysiol.00359.2005

Conflict of Interest: The authors declare that the research was conducted in the absence of any commercial or financial relationships that could be construed as a potential conflict of interest.

Copyright $\odot 2020$ Brechbuhl, Brocherie, Willis, Blokker, Montalvan, Girard, Millet and Schmitt. This is an open-access article distributed under the terms of the Creative Commons Attribution License (CC BY). The use, distribution or reproduction in other forums is permitted, provided the original author(s) and the copyright owner(s) are credited and that the original publication in this journal is cited, in accordance with accepted academic practice. No use, distribution or reproduction is permitted which does not comply with these terms. 